\title{
Using public encounter data to direct recovery efforts for the endangered smalltooth sawfish Pristis pectinata
}

\author{
Tonya R. Wiley ${ }^{1,2, *}$, Colin A. Simpfendorfer ${ }^{1,3}$ \\ ${ }^{1}$ Mote Marine Laboratory, Center for Shark Research, 1600 Ken Thompson Parkway, Sarasota, Florida 34236, USA \\ ${ }^{2}$ Present address: Texas Parks and Wildlife Department, Coastal Fisheries Division, 1502 FM 517 E, Dickinson, Texas 77539, USA \\ ${ }^{3}$ Present address: Fishing and Fisheries Research Centre, School of Earth and Environmental Sciences, \\ James Cook University, Townsville, Queensland 4811, Australia
}

\begin{abstract}
Conservation planning for difficult-to-survey endangered species can be challenging because information on distribution, abundance, and habitat associations is hard to gather. We used data provided by the public for an easily identified rare marine species, the endangered smalltooth sawfish Pristis pectinata, to provide information to direct recovery efforts in US waters. Data from public encounters from 1998 to 2008 occurring between Texas and Georgia were analyzed. Most records $(99.7 \%)$ were from Florida waters. Although all size classes were reported, the majority were sawfish $\leq 200 \mathrm{~cm}$ estimated total length. There was an inverse relationship between sawfish size and extent of northern distribution, with $\leq 200 \mathrm{~cm}$ animals having a wider latitudinal distribution and occurring farthest north, and $>200 \mathrm{~cm}$ animals reported mostly in southern Florida. Most encounters occurred in estuarine and nearshore habitats, and their locations were not randomly distributed, having positive association with inshore mangrove and seagrass habitats. While sawfish were reported in depths up to $73 \mathrm{~m}$, there was a significant relationship between size and depth, with smaller animals occurring in shallower waters. Although historically common from Texas to North Carolina, this study shows that the core range of smalltooth sawfish is now the area in Florida from the Caloosahatchee River south through the Ten Thousand Islands and Everglades National Park to Florida Bay. These results provide resource managers with information to direct recovery efforts, including the current range, areas where recovery may be expected to occur, and the habitat needs of various size classes.
\end{abstract}

KEY WORDS: Pristidae $\cdot$ Distribution $\cdot$ Habitat use $\cdot$ Endangered species $\cdot$ Conservation

\section{INTRODUCTION}

Developing recovery strategies for endangered marine species for which there are limited scientific data on distribution and habitat associations can be challenging, as it is difficult to identify areas on which to focus efforts. This is especially true for species that are widely dispersed and difficult to survey. One approach that can be useful in these situations is to use data from the public to augment scientifically collected data (Diemer \& Speake 1983, Epperly et al. 1995, Quinn 1995, Palma et al. 1999, Pike et al.
1999, Gese 2004). To be successful, such approaches need to target species that the public can easily identify and have rigorous mechanisms to ensure data quality. One group of benthic elasmobranchs, the sawfishes (family Pristidae), is ideally suited to this type of approach. The distinctive elongate toothed rostrum allows easy identification, all 7 currently recognized species are listed as Critically Endangered on the IUCN Red List (www.redlist.org), and there is limited scientific data to assist in recovery efforts (Simpfendorfer 2000, Peverell 2005, Carlson et al. 2007, Thorburn et al. 2007, 2008). 
The smalltooth sawfish Pristis pectinata Latham, 1794 was historically widely distributed within the coastal waters of the eastern and western Atlantic (Bigelow \& Schroeder 1953, Simpfendorfer 2005). In the western Atlantic, it historically occurred from New York to southern Brazil, including the Caribbean islands (Bigelow \& Schroeder 1953). Early accounts of P. pectinata in US waters indicate that this species was commonly encountered in nearshore areas (Goode 1884, Henshall 1895, Jordan \& Evermann 1896, Bigelow \& Schroeder 1953). Reports from the late 19th century documented a species that was regularly observed and caught from North Carolina to the USA/Mexico border (Goode 1884, Henshall 1895). Within Florida waters, sawfish were very common in coastal and estuarine areas on both the east and west coasts. For example, Evermann \& Bean (1898) recorded that a fisherman in the Indian River Lagoon on the east Florida coast reported capturing 300 sawfish in his nets in a single season. However, since the early 1900s, the population has declined substantially due to bycatch in fisheries (commercial and recreational) and coastal habitat degradation (Adams \& Wilson 1995, Simpfendorfer 2000, 2005). Although estimates of the exact magnitude of this population reduction are difficult to make due to the limited data (Simpfendorfer 2002), based on the contraction of the range and other anecdotal data it has been conservatively estimated that the decline in the population is in excess of $95 \%$ of the virgin stock size (NMFS 2000, Simpfendorfer 2002).

Concomitant with the decline in population size has been a severe contraction of the species' US range. By 2000 it was believed that the population was largely restricted to the waters of southern Florida, especially the marine and estuarine sections of the Everglades National Park and adjacent areas (Seitz \& Poulakis 2002, Simpfendorfer 2002, Poulakis \& Seitz 2004, Simpfendorfer \& Wiley 2005). Seitz \& Poulakis (2002) and Poulakis \& Seitz (2004) used public encounters of sawfish to demonstrate that all size classes of this species occurred in southwest Florida, Florida Bay, and the Florida Keys. However, the distribution of sawfish outside of these areas has remained undocumented in the scientific literature. In response to the decline in the Pristis pectinata population, the National Marine Fisheries Service (NMFS) listed this species as Endangered under the US Endangered Species Act (ESA) effective 1 May 2003. In 2009, NMFS published a recovery plan for this species in US waters (NMFS 2009). Delineation of the current range of $P$. pectinata will provide a baseline for determining subsequent changes. Understanding habitat associations throughout the species' range is necessary to allow essential features to be protected or restored. Through the creation and management of the National Sawfish
Encounter Database, the aims of this study were to gather public reports of encountered sawfish in order to (1) identify the methods of sawfish interactions and their conservation implications, (2) determine the current distribution of $P$. pectinata within US waters to identify areas where conservation and recovery efforts should be focused, and (3) describe habitat components within the current range that may be important for $P$. pectinata conservation and recovery efforts.

\section{MATERIALS AND METHODS}

Data collection. Information on the occurrence of Pristis pectinata was gathered between 1998 and 2008. To alert the public to the need for information on sawfish encounters, a broad range of awareness-raising tools was used, including flyers posted at boat ramps, tackle shops, bait stands, and dive shops; articles in fishing and other marine-oriented magazines and tourist information brochures; media releases; a web site; direct approaches to fishing guides, other researchers, and commercial fishers; presentations at scientific conferences, schools, and public meetings; and distributing 'Release It-Report It' campaign materials (e.g. buttons, stickers, t-shirts, pens, fishing license holders, brochures) at the aforementioned events. To ensure that the requests for information were spread evenly throughout Florida, the state was divided into 6 regions, and material distribution and awareness-raising activities were focused in each region on a biannual basis starting in June 2002. Starting in 2006, annual awareness-raising trips were also carried out to Gulf of Mexico states (Texas, Louisiana, Mississippi, and Alabama) and starting in 2007, to south Atlantic coast states (North Carolina, South Carolina, and Georgia).

A standard questionnaire form was completed when a sawfish encounter was reported, ensuring that the same data were collected for each encounter. The questions included the date and time of encounter, exact location of the encounter, the reporter's activity at the time of encounter, number of sawfish encountered, estimated total length, activity of the sawfish at the time of encounter, whether the sawfish was captured or simply observed, if captured how it was captured, habitat at the site of the encounter, water depth, tidal state, and other physical and environmental parameters. For encounters reported by researchers, exact length measurements were often available, along with sex and reproductive condition of males. Total lengths of most other sawfish were estimated during public encounters and probably had a wide degree of error. To enhance the public sightings database, many charter fishing captains participated in a Captain's Logbook Program. 
Participating captains were given a logbook of preprinted postcards to be filled in with the same information as that required on the sawfish reporting form.

A rigorous set of criteria was used for inclusion of encounter reports in the database. First, the species encountered must have been confirmed as a sawfish. To eliminate residual uncertainty and verify species identification (Stiles 1983), reporters were asked to supply photographs or video whenever possible. When photographs or video were not available, a series of questions about the form of the body (e.g. color, presence and number of lateral rostral teeth, rostrum shape, possession and location of gill openings) was asked to distinguish sawfish from guitarfish Rhinobatis lentigulosis, saw sharks Pristiophorus spp., gars Lepisosteus spp., and paddlefish Polyodon spatula. Second, only observations reported within 3 mo of an encounter were included, as the probability of receiving accurate data (exact location and/or date) decreases with time after the observation (Westat, Inc. 1989, Essig \& Holliday 1991). Third, only observations which included a location that could be accurately determined (<500 m uncertainty) were included since the data were intended to be analyzed using a Geographic Information System (GIS). The widespread use of global positioning system (GPS) technology in recent years increased the accuracy with which many people reported locations. When GPS locations were not available, reporters were asked to provide detailed information on the location of their observation (location relative to local landmarks, a map showing the location, etc.). Encounter reports were stored in a Microsoft Access database.

Data analysis. Encounter data were plotted in a GIS (ArcView 3.3, ESRI) for analysis. Encounter data were converted to encounter density by counting the number of data points within a $0.1^{\circ}$ grid using the Spatial Analyst extension for ArcView 3.3. Although a wide range of habitat data were provided with encounter reports, the inconsistent nature by which it was observed and reported made it impossible to use this information in any quantitative analysis. The exception to this was depth, which the reporters were able to accurately record due to direct observation and the widespread use of depth sounders. As most total length and depth estimates were provided in feet, all reported measurements were converted to metric units for the database. When a reporter supplied a length range for the encountered sawfish, the median value was entered for length (i.e. the reporter estimated the length of the sawfish as 4 to 5 feet, then $137 \mathrm{~cm}$ [4.5 feet] was entered).

To examine the importance of habitat associations other than depth, the proximity of encounters to 3 features, viz. the shoreline, mangroves, and seagrasses, was calculated in the GIS. GIS shapefiles for each of these features were obtained from the Florida Geographic Data Library (www.fgdl.org), and the shortest distance from encounter locations to the closest occurrence of each feature was calculated using the Nearest Features (v. 3.7) extension for ArcView. Three analyses were performed on these data. First, the relationships between the distances and the total length of the sawfish were calculated by fitting a linear regression to the data. The distance-to-feature data were $\log (x+1)$ transformed to normalize the data before fitting the regressions. Second, the relationship between water depth and sawfish size was examined in the same way. Third, the frequency distributions of the distance-to-feature data were compared to values from a randomized set of points to determine if sawfish observations occurred closer to a feature than would have been expected by random chance. To do this, 1000 randomly located points were created using the random point generator extension for ArcView 3.3, v. 1.3. (Jenness 2005) within the depth range of 0 to 12 feet $(0$ to $3.6 \mathrm{~m})$, the closest Florida bathymetry GIS shapefile available from the Florida Geographic Data Library. The distance-to-feature of these points for the shoreline, mangroves, and seagrass was then calculated. For comparison to the randomized points, encounters within the same depth range were selected, and the distance-to-features was calculated. The 2 sets of distances were then $\log (x+1)$ transformed, and a $t$-test was used to determine if the observations occurred closer to the feature than was expected.

\section{RESULTS}

\section{Encounters}

The National Sawfish Encounter Database received 1065 reports from January 1998 to August 2008. In total, 1004 validated sawfish encounter records for US waters were used in the analyses (Fig. 1). Sawfish sightings and captures occurred during a wide variety of activities, with the majority $(64.2 \%)$ of encounters occurring while people were fishing, although not all of the encounters which occurred while fishing were captures. The second most common activity resulting in encounters was research $(21.7 \%)$. Most of these encounters occurred during the authors' directed sawfish field research and Rookery Bay Estuarine Re0search Reserve shark research in the Ten Thousand Islands, with a small number from other scientific activities such as sea turtle research and bird surveys. Boaters reported $6.0 \%$ of sightings, and divers and snorkelers $3.6 \%$. Reports from people engaged in other activities such as walking the shoreline and per- 


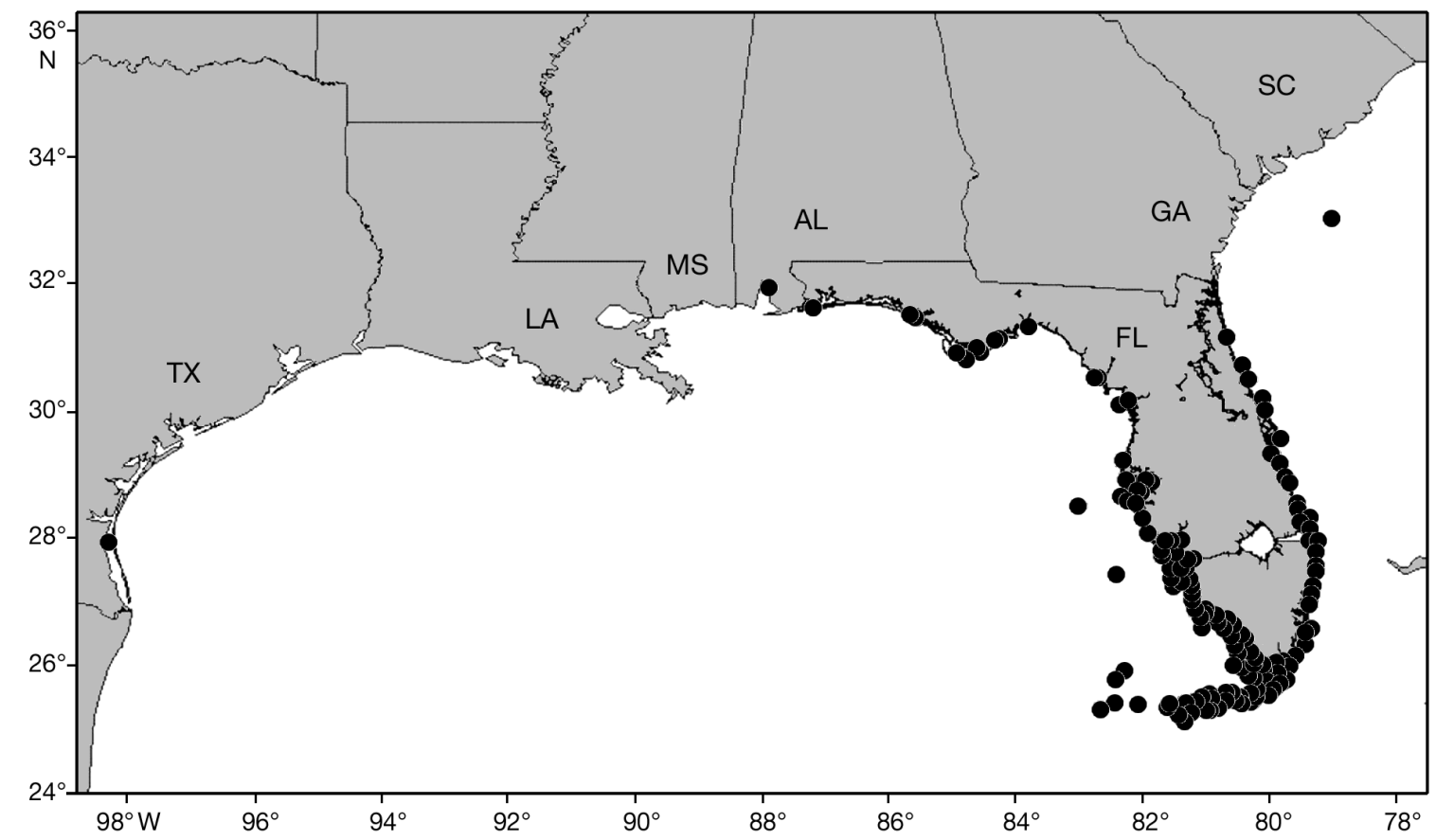

Fig. 1. Pristis pectinata. Distribution of reported encounters with smalltooth sawfish along the US coast, 1998 to 2008

forming aerial surveys accounted for the remaining $4.5 \%$ of encounters.

Sawfish were captured during $57.9 \%$ of the reported encounters, and rod and reel was the most common method of capture $(62.2 \%$; Table 1$)$. Fishers who captured sawfish reported that they were targeting a wide range of fish species (Table 2), with the most commonly targeted species being sharks, snook Centropomus undecimalis, tarpon Megalops atlanticus, and red drum Sciaenops ocellatus. The majority of fishing encounters were by recreational fishers or fishing guides operating in nearshore Florida waters. The database contained 6 records $(0.6 \%)$ of dead stranded sawfish (2 of which were recovered by the authors for necropsy) and only 5 records $(0.5 \%)$ of sawfish retained by fishers, demonstrating very high rates of release.

Table 1. Pristis pectinata. Method of capture of reported smalltooth sawfish encounters in the US, 1998 to 2008

\begin{tabular}{|lc|}
\hline Method of capture & Reports (\%) \\
\hline Rod and reel & 62.2 \\
Unknown/not reported & 21.1 \\
Turtle trawl & 6.7 \\
Longline & 5.5 \\
Gill/entanglement nets & 2.4 \\
Seine net & 1.4 \\
Castnet & 0.3 \\
Shrimp trawl & 0.2 \\
Lobster pot rope & 0.2 \\
\hline
\end{tabular}

\section{Spatial and temporal distribution}

One confirmed report was received from each of the states Texas, Georgia, and Alabama (Fig. 1). An additional report was received from Louisiana, and although definitely a sawfish, was not included in the analysis, as a location that met the criteria for inclusion in the database could not be determined. The remaining 1001 sawfish encounters occurred within Florida waters; from Pensacola $\left(87.2^{\circ} \mathrm{W}\right)$ in the Panhandle to St. Augustine $\left(29.9^{\circ} \mathrm{N}\right)$ on the northeast coast. Most

Table 2. Target species of reported smalltooth sawfish Pristis pectinata captures in the USA, 1998 to 2008. Total percentage exceeds $100 \%$ because some reporters were targeting multiple species at time of sawfish capture

\begin{tabular}{|lcc|}
\hline Target & Latin name & \% of reports \\
\hline Sharks & & 46.4 \\
Snook & Centropomus undecimalis & 19.4 \\
Tarpon & Megalops atlanticus & 15.1 \\
Redfish & Sciaenops ocellatus & 13.0 \\
Snappers & Lutjanidae & 4.2 \\
Goliath grouper & Epinephelus itajara & 2.1 \\
Trout & Cynoscion spp. & 1.4 \\
Cobia & Rachycentron canadum & 1.4 \\
Mullet & Mugil spp. & 1.4 \\
Shrimp & Penaeidae & 1.4 \\
Anything & Ariidae & 1.4 \\
Catfish & Archosargus probatocephalus & 0.7 \\
Sheepshead & 0.7 \\
\hline
\end{tabular}


occurred in the southwest coastal region from the Caloosahatchee River $\left(26.7^{\circ} \mathrm{N}\right)$ to Florida Bay $\left(24.9^{\circ} \mathrm{N}\right.$; Fig. 1).

The spatial distribution of encounters within Florida varied annually. The northernmost encounter on the east coast occurred in 2000 near St. Augustine $\left(29.9^{\circ} \mathrm{N}\right)$ and on the west coast in 2005 near Pensacola $\left(30.3^{\circ} \mathrm{N}\right)$. Reports were received from the east coast in all study years, with the most $(n=7)$ in 2007. In 1999, all east coast reports were from the upper coast (north of $29.0^{\circ} \mathrm{N}$ ), and in 2006 , all were from the central coast (between $26.0^{\circ}$ and $26.5^{\circ} \mathrm{N}$ ). A single report was received from the east coast in 1998 and 2002. On the west coast, encounters were reported from the Panhandle in 2001 to 2006. In 1999 and 2008, the northernmost west coast reports were from Tampa Bay $\left(27.8^{\circ}\right.$ and $27.5^{\circ} \mathrm{N}$, respectively), in 2000 from Crystal River $\left(28.9^{\circ} \mathrm{N}\right)$, and in 1998 and 2007 from lower Charlotte Harbor $\left(26.4^{\circ}\right.$ and $26.9^{\circ} \mathrm{N}$, respectively). Reports were received from the Florida Keys each year, and in all years the region from the Ten Thousand Islands to Florida Bay was the area with the highest number of encounter reports (Fig. 1).

The number of encounters reported annually increased steadily from 1998 to 2002, peaked in 2004, and then decreased steadily through 2008 (Fig. 2). Encounters did not occur evenly throughout the year (chi-squared test, $\chi^{2}=226.72, \mathrm{df}=11, \mathrm{p}<0.01$ ), with the highest proportion of encounters occurring from March through April, and the lowest from September through January (Fig. 2).

Encounter density identified areas with the highest probability of sawfish occurrence (Fig. 3). The Ten Thousand Islands and central Everglades coast were areas where field research had been focused, and thus may have represented areas of disproportionately high observational effort. To remove the potentially biasing research effort, encounter densities were calculated without researcher-reported encounters. Four areas with the highest encounter densities $\left(>0.151\right.$ encounters $\mathrm{km}^{-2}$ ) were identified: the lower Caloosahatchee River, Ten Thousand Islands/northern Everglades National Park coast from Palm Bay to Sunday Bay, central Everglades National Park coast from Lostman's River to northern Ponce de Leon Bay, and northern Florida Bay coast from East Cape to Garfield Bight (Fig. 3). These areas are at the mouths of major rivers or other sources of freshwater flow (i.e. Everglades freshwater flow). North of this area on the west coast of Florida, peaks in encounters corresponded

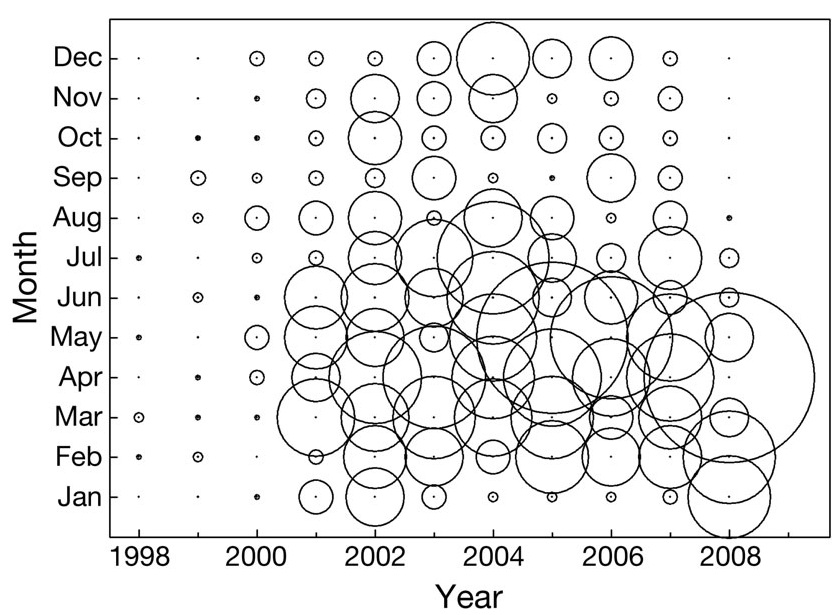

Fig. 2. Pristis pectinata. Temporal distribution of smalltooth sawfish encounters reported in the USA, 1998 to 2008. Small dots indicate no data; diameter of circle is proportional to number encountered

with the mouths of major rivers: Peace, Myakka, Manatee, Hillsborough, Withlacoochee, and Suwannee Rivers (and their associated estuaries). On the east coast and Panhandle, encounters were not associated with river mouths, but instead were mostly at sandy beaches or in deeper water. There were no areas with encounter rates greater than 0.151 encounters $\mathrm{km}^{-2}$ on the east coast of Florida or on the west coast north of the mouth of the Caloosahatchee River.

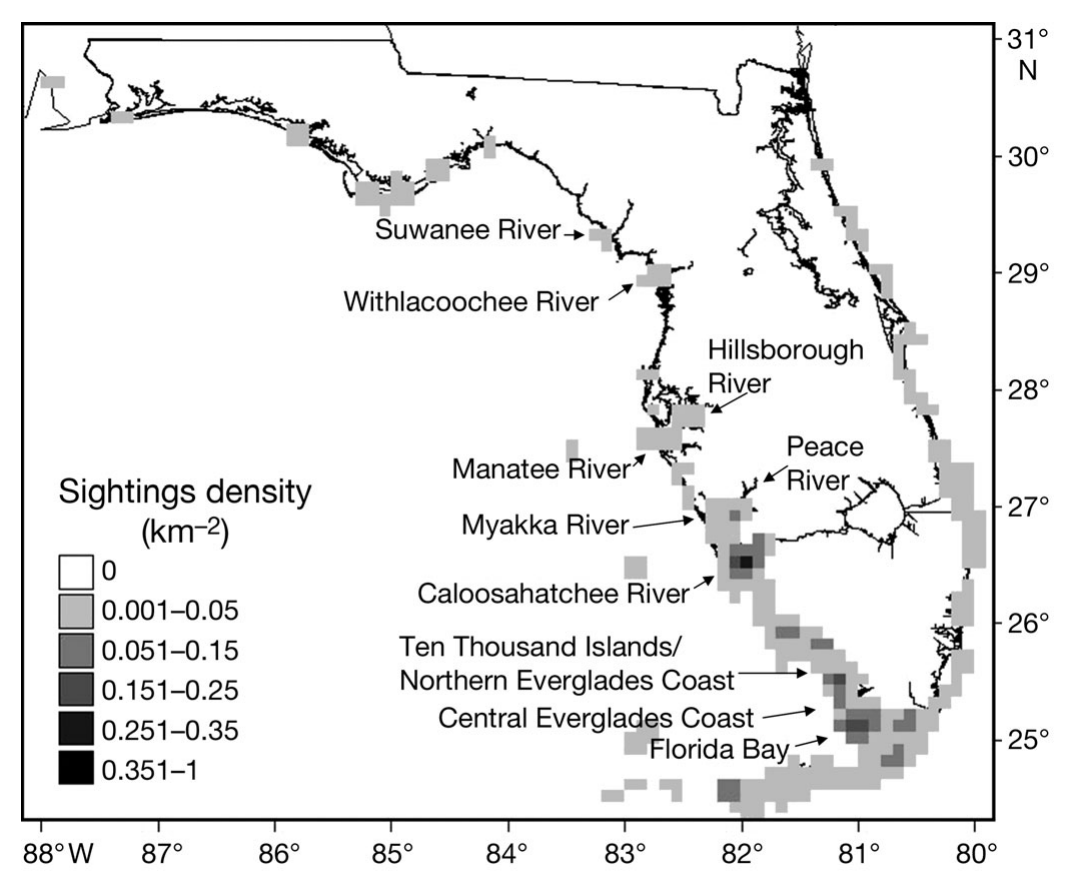

Fig. 3. Pristis pectinata. Smalltooth sawfish encounter density for nonresearch related reports in Florida, 1998 to 2008, in $0.1^{\circ}$ (latitude and longitude) geographic blocks 
Size

Pristis pectinata ranging in size from 45 to $606 \mathrm{~cm}$ were reported. The most commonly reported sizes were from 50 to $200 \mathrm{~cm}$ (Fig. 4). The number of animals encountered declined above approximately $150 \mathrm{~cm}$. There were significant differences in the mean monthly size of encountered sawfish (ANOVA, $F=$ 3.74, $\mathrm{p}<0.001$, df = 11). A post hoc comparison of means (Duncan test, $\alpha=0.05$ ) identified 4 mostly overlapping groups of months. The largest mean sizes were generally observed during the months from March through September.

Within Florida, there appeared to be an inverse relationship between size and northern distribution, with the smallest animals occurring the farthest north (Fig. 5). The smallest size group $(<100 \mathrm{~cm})$ had the broadest distribution within Florida, and the most northerly occurrence on both the east and west coasts (Fig. 6a). However, reports of sawfish $<100 \mathrm{~cm}$ were low in the Florida Keys and were absent from the southeast Florida coast. The $100-200 \mathrm{~cm}$ size class had a similar west coast distribution to that of the $<100 \mathrm{~cm}$ size class, but was not encountered north of Melbourne $\left(28^{\circ} \mathrm{N}\right)$ on the east coast (Fig. 6b). Sawfish $>200 \mathrm{~cm}$ were encountered from the Florida Panhandle to Cape Canaveral and were the only size class reported north of Florida on the Atlantic coast (1 sawfish reported off Georgia) (Fig. 6c,d). Animals of all size classes were reported throughout the Ten Thousand Islands, Everglades National Park, and the Florida Keys.

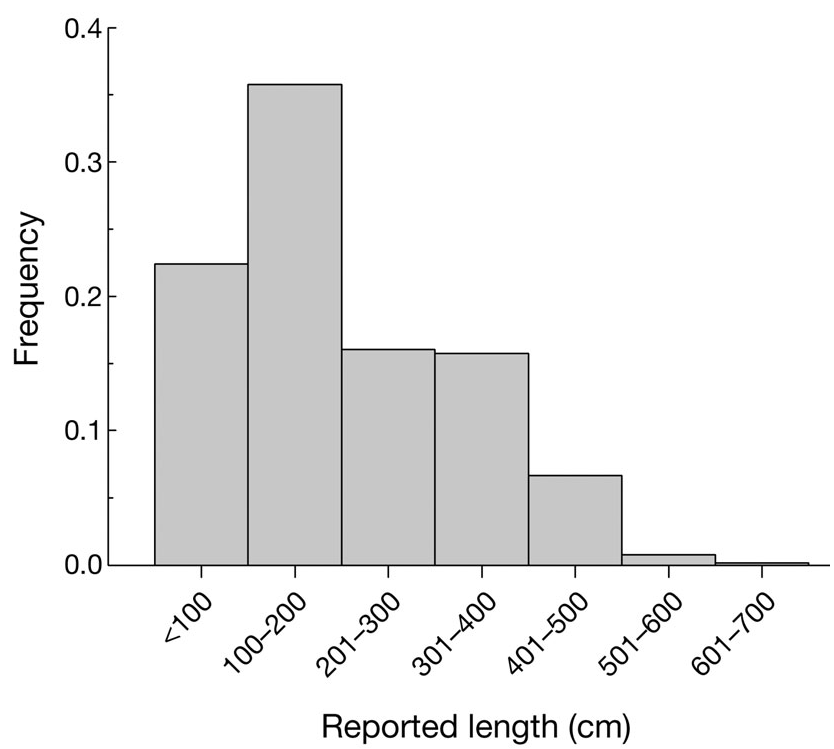

Fig. 4. Pristis pectinata. Frequency distribution of estimated total lengths of smalltooth sawfish from reported encounters in the USA, 1998 to 2008

\section{Habitat associations}

Sawfish encounters were reported in waters from 0.1 to $73 \mathrm{~m}$ deep. The vast majority $(88.5 \%)$ of encounters occurred in water $\leq 5 \mathrm{~m}$ deep (Fig. 7a), with a very small fraction occurring in water $>8 \mathrm{~m}$ deep. For encounters that occurred at depths $\leq 5 \mathrm{~m}$, most (58.1\%) were in $<1 \mathrm{~m}$. There was a significant relationship between depth and estimated length, with smaller animals tending to occur in shallower water $\left(R^{2}=0.346\right.$, slope $=0.0038, t=22.46, \mathrm{p}<0.001 ;$ Fig. 8a). This is further supported by the observation that the proportion of sawfish observed in depths $>5 \mathrm{~m}$ increased with increasing size: only $0.93 \%$ of sawfish $<100 \mathrm{~cm}$ were observed at depths $>5 \mathrm{~m}, 2.77 \%$ for lengths of $100-$ $200 \mathrm{~cm}, 17.02 \%$ for lengths of $201-340 \mathrm{~cm}$, and $35.44 \%$ for lengths $>340 \mathrm{~cm}$.

The majority of sawfish encounters occurred within $1.0 \mathrm{~km}$ of shore, with most occurring within $200 \mathrm{~m}$ (Fig. 7b). The number of encounters decreased regularly from 0.2 to approximately $1.5 \mathrm{~km}$, remained at a relatively constant low level until $4.0 \mathrm{~km}$, and then became more sporadic up to $9.0 \mathrm{~km}$. The mean distance to the shore was significantly less for the observations than it was for the randomized points ( $t$-test, $t=$ -7.12, $\mathrm{p}<0.0001$ ), indicating a positive association. There was a weak positive linear relationship $\left(\mathrm{R}^{2}=\right.$ 0.060 , slope $=0.0045, t=7.92, \mathrm{p}<0.001$ ) between estimated length and distance from shore, indicating that larger individuals tended to occur farther from shore (Fig. 8b).

A substantial proportion of nearshore encounters were recorded within $0.2 \mathrm{~km}$ of mangroves; the proportion then steadily declined until a distance of $3.0 \mathrm{~km}$ and then remained at a low level (Fig. 7c). Compared to the ran-

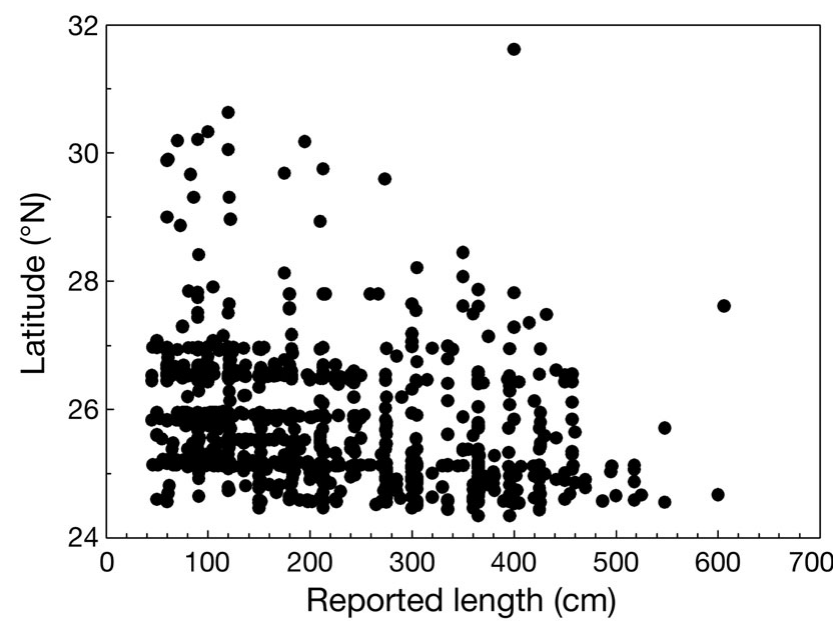

Fig. 5. Pristis pectinata. Latitudinal distribution of reported smalltooth sawfish encounters in the USA, 1998 to 2008, as a function of estimated total length 

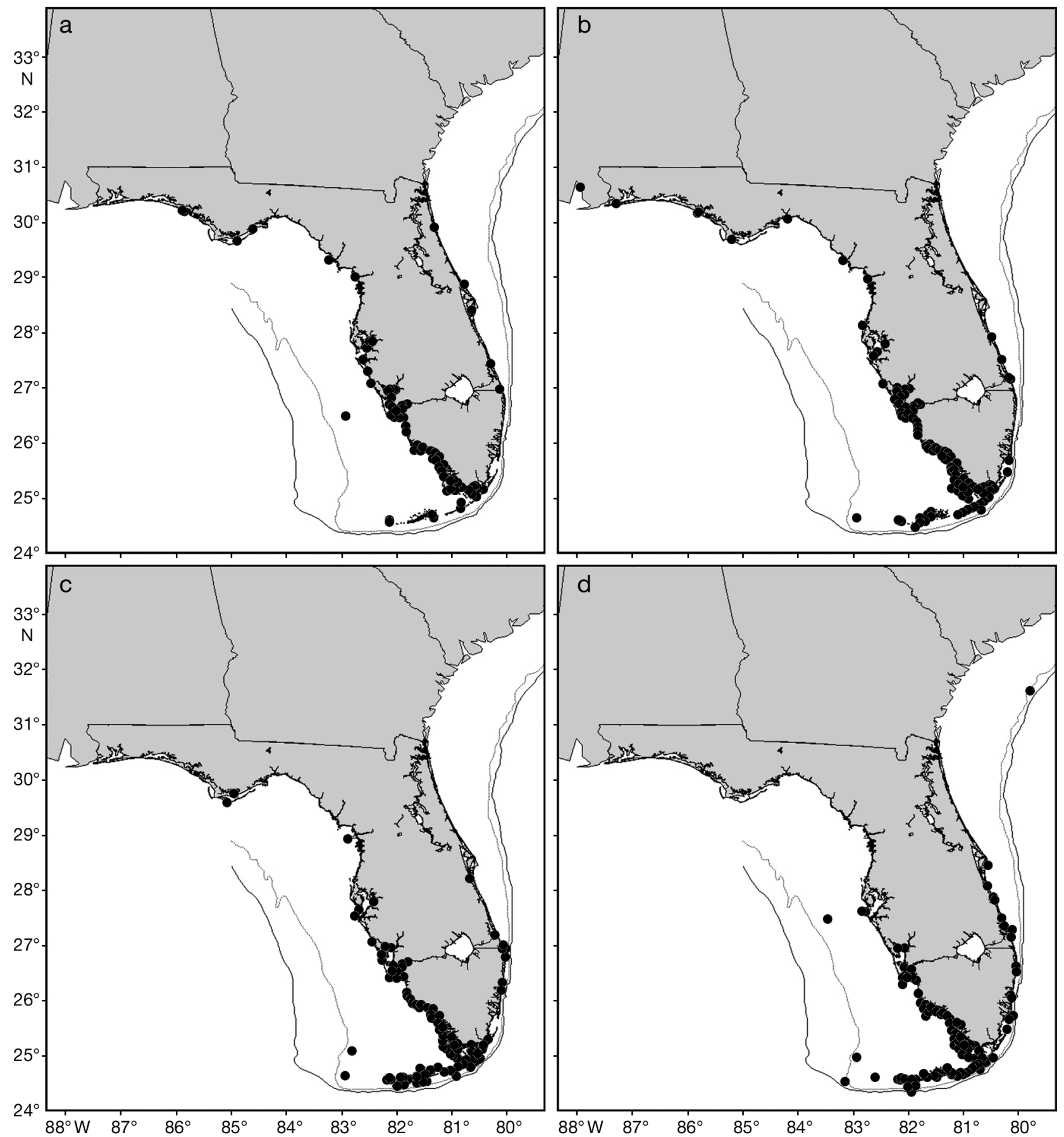

Fig. 6. Pristis pectinata. Geographic distribution of reported smalltooth sawfish encounters around Florida, USA, 1998 to 2008 , by estimated total length size class: (a) very small juveniles $<100 \mathrm{~cm}$; (b) small juveniles $100-200 \mathrm{~cm}$; (c) large juveniles 201-340 cm; (d) adults $>340 \mathrm{~cm}$. Light and dark lines are 50 and $100 \mathrm{~m}$ bathymetry contours, respectively

domized points, the observations were significantly closer to mangroves ( $t$-test, $t=-15.18, \mathrm{p}<0.0001)$, indicating a positive association. There was a significant positive relationship between estimated sawfish length and distance to mangroves $\left(\mathrm{R}^{2}=0.083\right.$, slope $=0.0047, t=$
9.37, p < 0.001; Fig. 8c), indicating that larger sawfish tended to be encountered farther from mangroves.

The largest proportion of sawfish encounters occurred more than $10.0 \mathrm{~km}$ from seagrass beds (Fig. 7d). However, the next most common group 

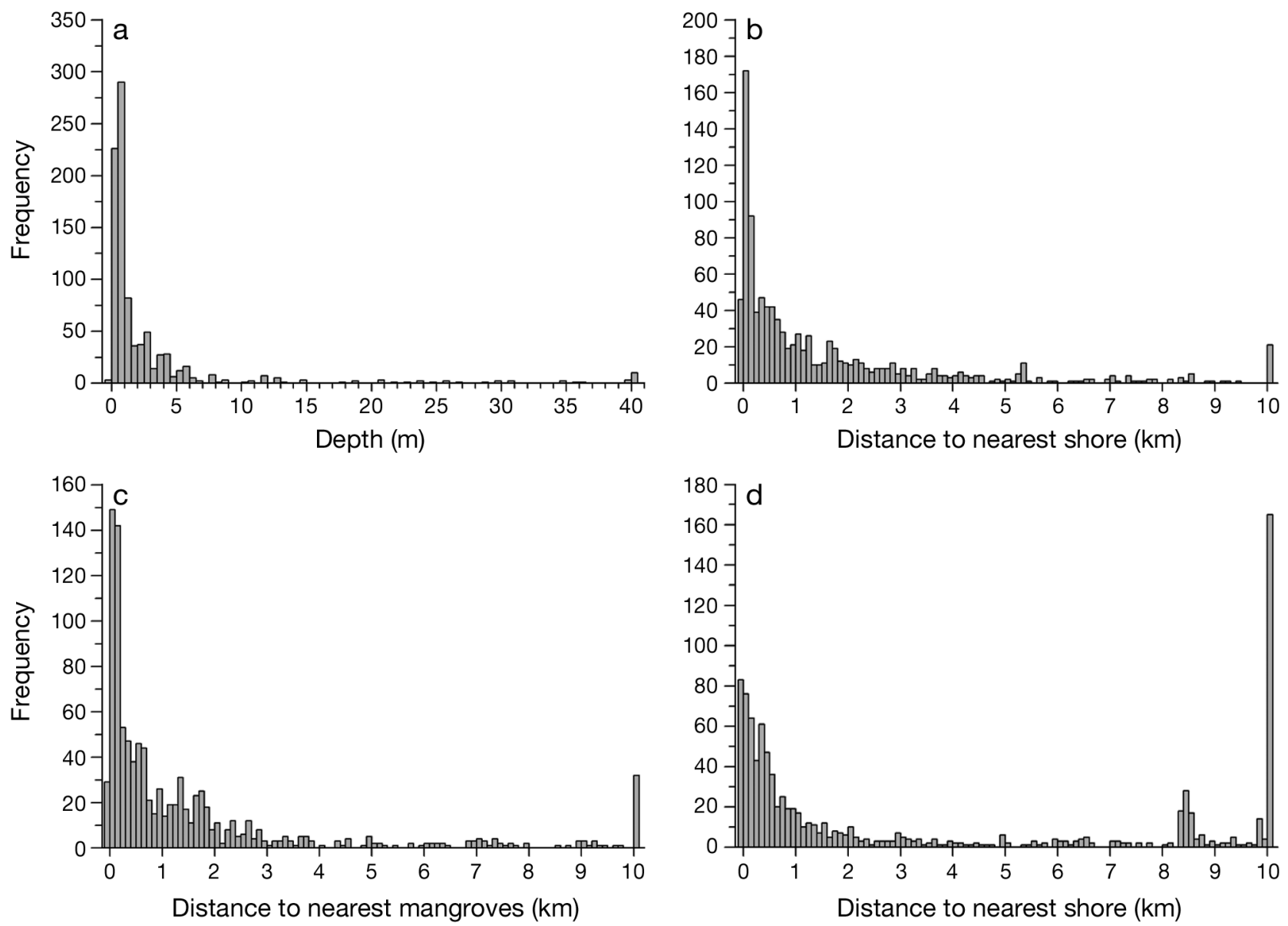

Fig. 7. Pristis pectinata. Frequency distributions of (a) reported water depth, and (b-d) distances to habitat features, for encounters with smalltooth sawfish. Distances to (b) shore, (c) mangroves, and (d) seagrass were calculated in ArcView 3.3 as the closest distance from the location of an encounter to the edge of a shape-file describing each feature. Data are all years (1998 to 2008) combined

occurred within seagrass beds, and there was a declining trend in encounter numbers with increasing distance up to approximately $2.0 \mathrm{~km}$. Sawfish occurred closer to seagrasses than the random points ( $t$-test, $t=$ $-3.33, p=0.0004$ ), indicating a positive association. No relationship was found between length and distance to seagrass beds $\left(\mathrm{R}^{2}=0.011\right.$, slope $=-0.0024, t=-3.23$, $\mathrm{p}=0.001 ;$ Fig. 8d).

\section{DISCUSSION}

\section{Utility of public encounter data}

The public encounter data provided to the National Sawfish Encounter Database has been an excellent tool to monitor the smalltooth sawfish population in the southeast USA. The analysis of these observations will help focus conservation efforts and provide a baseline from which to examine changes in the distribution as the population recovers. Although this study was focused on the distribution of sawfish in the USA, information was also received on sawfish from Australia, Costa Rica, Panama, Cuba, and the Bahamas, indicating that the outreach efforts and networking were widely effective and may be a useful tool in other regions where data on Pristis pectinata, or other sawfish species, are required.

The results of this study demonstrated that awareness-raising efforts are required to ensure the ongoing provision of public encounter data. The number of reports to the National Sawfish Encounter Database increased in 2001, corresponding to the beginning of dedicated full-time outreach efforts. The highest number of sawfish encounter reports was received in 2004 . The decline of sawfish reports after 2004 could be the result of several factors. First, several hurricanes in 2004 and 2005 reduced the number of fishable days and destroyed many fishing access points (such as piers, marinas, and vessel launching ramps) through- 

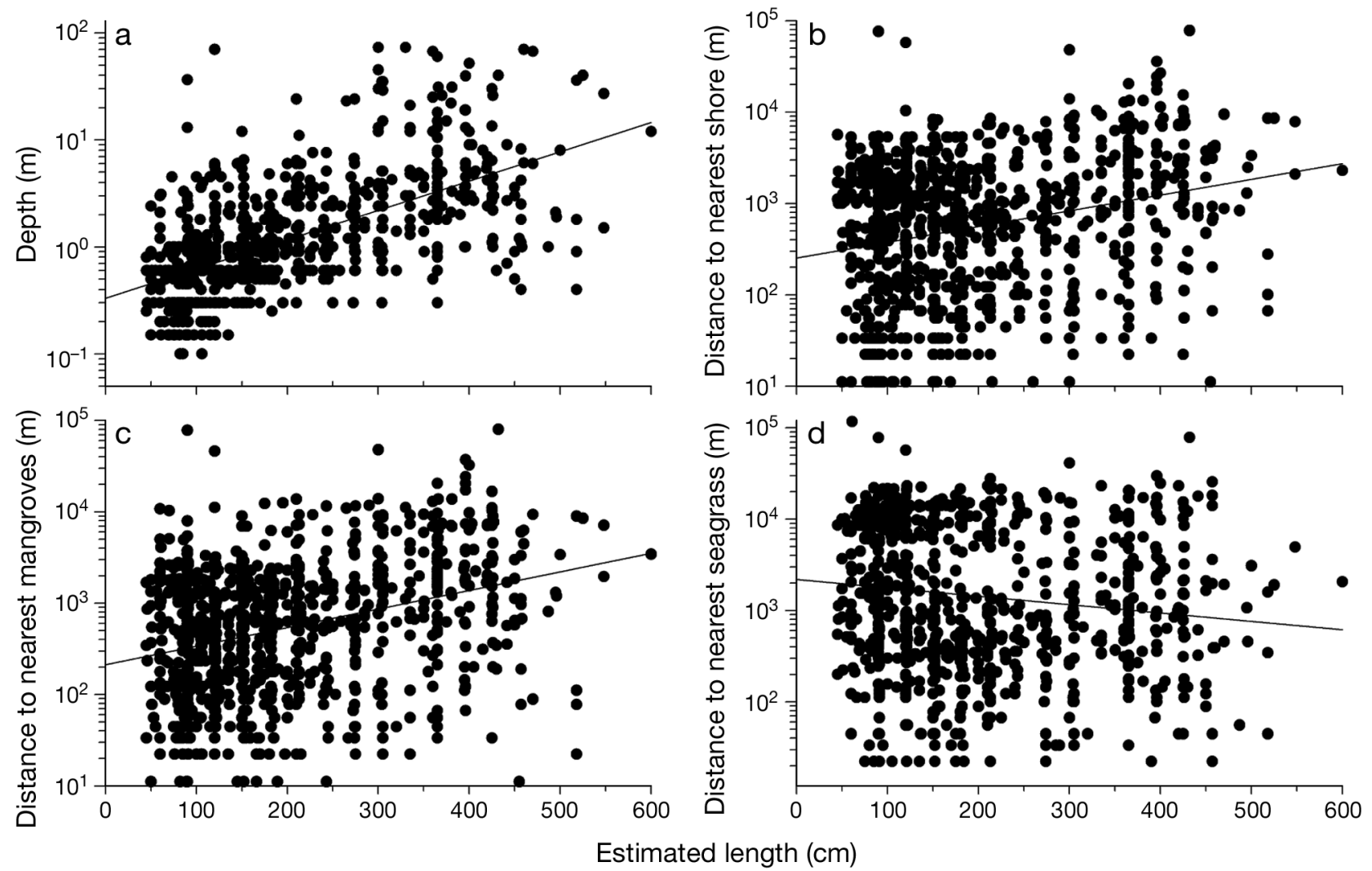

Fig. 8. Pristis pectinata. Relationships between estimated total lengths of smalltooth sawfish P. pectinata and (a) depth, (b) distance to shore, (c) distance to mangroves, and (d) distance to seagrass. Distances were calculated in ArcView 3.3 as the closest distance from the location of an encounter to the edge of a shape-file describing each feature. Data are all years (1998 to 2008) combined

out southwest Florida, including Flamingo in the Everglades National Park. The closure of Flamingo facilities greatly reduced the accessibility of many areas of Everglades National Park. Second, many people became reluctant to report sawfish encounters once the species was listed as an Endangered Species in 2003. In light of the protections afforded by the ESA, some fishers were apprehensive to continue to report sawfish encounters, fearing their 'favorite fishing hole' would be closed or restricted due to the presence of sawfish. Third, due to the endangered status of sawfish, fishing magazines and newspapers were not publishing as many public submissions and photographs of sawfish captures, thereby reducing the numbers of sawfish encounters followed up on from this source.

The distribution of sawfish encounters was dependent on many factors, but two that were important in interpreting the results were the actual distribution of the species and the distribution of the observational effort. If the observational effort was uneven it could lead to misinterpretation of the distribution. By conducting awareness-raising activities from Texas to North Carolina, this study ensured the majority of the historic range of sawfish in US waters was included. In addition, research observations were excluded when processing the data to estimate encounter density, as this observational effort was focused mostly in the core range and so was not evenly distributed. It was impossible to ensure that the spatial and temporal distribution of observational effort was even across the state, and the results must be interpreted in light of this. Recreational fishing (the main source of encounter reports) is popular throughout Florida; however, there is a lower population density in the Panhandle and upper west coast than in southern Florida (Simpfendorfer \& Wiley 2005). It is unlikely that the resulting difference in observational effort would affect the interpretation of distribution; nevertheless, this difference makes investigating abundance (or changes in abundance over time) from these data impossible.

\section{Effects of recreational fishers}

The results of this study demonstrated that recreational fishing is currently the major activity that 
directly interacted with Pristis pectinata throughout most of its range. These fishers were not targeting $P$. pectinata, but instead captured them incidentally. When reporters captured a sawfish while fishing, they were most commonly targeting sharks. Other common target species associated with captures of sawfish were snook, red drum, sea trout, and tarpon. Using data from creel surveys in Everglades National Park, Carlson et al. (2007) found that the species with the highest associated statistic with the catch of $P$. pectinata was the goliath grouper Epinephelus itajara. Since E. itajara is currently protected in Florida waters, fishers rarely reported it as a target species in this study. The next 9 species reported by Carlson et al. (2007) were mostly similar to those reported in the current study: nurse sharks, blacktip sharks, requiem sharks, pinfish, tarpon, snook, red drum, crevalle jack, and gafftopsail catfish. Given the range of species that $P$. pectinata were captured in association with, efforts to educate recreational fishers about handling and release of sawfish must be broad-based.

One recovery objective of the US Smalltooth Sawfish Recovery Plan (NMFS 2009) is to minimize human interactions and associated injury and mortality. The high release rate of Pristis pectinata by recreational fishers observed in this study suggests that although interaction rates may be relatively high, fishers mostly comply with regulations that require these animals be released unharmed. It is currently unknown what effects capture and handling by recreational fishers have on P. pectinata. Seitz \& Poulakis (2006) reported that sawfish are capable of becoming entangled in, and injured by, a variety of anthropogenic debris, including discarded fishing gear (e.g. hooks and line). However, the results of acoustic tracking and monitoring of $P$. pectinata captured by a variety of gear, including hook and line, had high survival levels for periods up to several months (Simpfendorfer et al. 2010), suggesting that post-release survival can be high if appropriate handling and release procedures are employed. Continuing education of anglers should therefore aid in mitigating negative effects of the recreational fishery on the recovering population. In addition to the collection of data on recreational captures, the National Sawfish Encounter Database represents an ongoing outreach activity that helps to educate fishers about the conservation needs and appropriate handling practices of this species.

\section{Distribution}

The use of public encounter data within the National Sawfish Encounter Database has provided the first comprehensive view of the current Pristis pectinata distribution within US waters. The results of this study demonstrate that the population is currently most common in the southwestern region of Florida, with the core range now the area from the mouth of the Caloosahatchee River south through the Ten Thousand Islands and Everglades National Park to Florida Bay. The occurrence of $P$. pectinata decreased with increasing distance from this core area, but they appeared to be encountered more commonly on the west coast of Florida and in the Florida Keys than on the east coast of Florida. These data agree with the observations of Seitz \& Poulakis (2002) and Poulakis \& Seitz (2004) that this species occurs throughout southwest Florida, Florida Bay, and the Florida Keys, but extends the range of observations beyond the scope of these prior studies to determine the distribution on a broad scale. The occurrence of $P$. pectinata outside of Florida appears to be rare, with only very small numbers of encounter reports, despite awareness-raising efforts. The core range of $P$. pectinata corresponds to the segment of Florida with the smallest amount of coastal habitat modification. The establishment of the Everglades National Park (ENP) in 1947, which protected coastal habitats, and the banning of commercial fishing in ENP in 1986 probably played an important role in this area remaining important for $P$. pectinata while their abundance in many other areas declined.

The encounter data indicate that Pristis pectinata currently do not occur, or are rarely found, in some areas of documented historical importance. Few encounters were reported in the Indian River Lagoon system that historically supported large numbers of sawfish (Goode 1884, Henshall 1895, Jordan \& Evermann 1896, Evermann \& Bean 1898). This observation corroborates the conclusion of Snelson \& Williams (1981) that this species had been virtually extirpated from the system. Bigelow \& Schroeder (1953) reported that $P$. pectinata were also common in the lower reaches of the St. Johns River, but no encounters were reported from that area during our study. Based on these observations, it appears that the depletion of $P$. pectinata has been most dramatic on the east coast of Florida. Recovery efforts could therefore be best targeted at these areas of historic abundance, but will need to address issues related to the loss of important habitats and other anthropogenic effects.

The current geographic distribution of Pristis pectinata appears to be relatively static. The overall range does not appear to have changed markedly from 1998 to 2008. Annual changes in the northern extent of the range are likely due to insufficient abundance of $P$. pectinata in the outer areas to ensure that individuals were consistently observed from year to year. The results also suggest that it is the smallest size classes ( $\leq 200 \mathrm{~cm}$ estimated length) that currently have the 
broadest distribution and the only size classes which regularly occurs in north Florida. This observation conflicts with historic accounts, especially from the east coast, that provide substantial information on the summer migration of adult individuals north of Florida as far as New York (Bigelow \& Schroeder 1953). However, there has been little evidence that this migration currently occurs. To our knowledge, there has been only 1 recent record of a sawfish north of Florida, an adult animal caught by a bottom longline vessel in over $60 \mathrm{~m}$ of water off the north coast of Georgia (G. Burgess pers. comm.). Given the scarcity of encounter reports from the northeast Florida coast, it is possible that the segment of the population which undertook this migration has declined to a level where the migration is now undetectable or is not occurring. Tracking using satellite telemetry may help to better define the spatial dynamics of larger sawfish and provide insight into the status of the migrations of adult sawfish.

\section{Size}

The full size range of Pristis pectinata was recorded in Florida waters during this study. The prevalence of juvenile size classes, including animals that had neonate characteristics (e.g. presence of sheath on the rostrum), indicate that the population remains reproductively active and viable. The higher number of encounters reported during spring is likely the result of recruitment into the population. The size at birth for $P$. pectinata in Florida is 69 to $81 \mathrm{~cm}$ (Simpfendorfer et al. 2008). Seitz \& Poulakis (2002) and Poulakis \& Seitz (2004) also reported that within the geographic range of their studies (southwest Florida, Florida Bay, and the Florida Keys), all size classes were present. The rarity of juveniles in the Indian River Lagoon system indicates that although the population is reproducing, pupping in this historically important area is currently limited. Recovery efforts focusing on how to re-establish recruitment in this area would enhance survival of the species by providing geographically dispersed nursery habitats. Such diversification would guard against stochastic events such as hurricanes, red tide blooms, oil spills, cold weather and freezes, and disease, which could negatively influence the viability of the population.

At the broader scale, the current study did not record adult sized individuals ( $>340 \mathrm{~cm}$, Simpfendorfer et al. $2008)$ in Florida north of Tampa Bay $\left(28^{\circ} \mathrm{N}\right)$ on the west coast and Cape Canaveral $\left(28.4^{\circ} \mathrm{N}\right)$ on the east coast, suggesting adults are rarely occurring in this region. However, the occurrence of small juveniles (at sizes close to those at birth) in the Florida Panhandle suggests that adult females may occur in this area at least to give birth. Although the small juveniles may move northwards after birth, in most elasmobranch populations parturition occurs in, or very close to, their nursery areas (Springer 1967, Branstetter 1990, Simpfendorfer \& Milward 1993). The low number of reports of sawfish $<100 \mathrm{~cm}$ from the Florida Keys suggests that parturition in this area is limited. However, the current study shows that the smalltooth sawfish population outside of the southwest Florida coast and Florida Keys is very small, so most of the reproduction is currently limited to a fraction of this species' former range.

\section{Habitat associations}

The results of this study demonstrate that public encounter data can be used to examine habitat associations of endangered aquatic species. The data collected indicate that Pristis pectinata are closely associated with a number of habitat features. These include shallow waters, and areas close to shore, mangroves and seagrasses. However, 2 factors make the interpretation of these associations difficult. Firstly, there is a high degree of correlation between these habitats. For example, proximity to shore may be a function of selection of shallow depths or mangrove areas. Telemetry results for juvenile $P$. pectinata (Simpfendorfer et al. 2010) indicate that they selectively use habitat based both on depth and mangrove presence, supporting the results of the current study. The second factor making interpretation of the associations more difficult is that although encounters occurred closer to the shore, mangroves, and seagrass beds than was expected at random, there was no information on the fine-scale distribution of the observational effort. Since the teleost species that fishermen commonly target when they encounter sawfish (e.g. snook and redfish) are closely associated with mangroves (Pattillo et al. 1997), it is likely that greater observational effort would have occurred in these areas and so may have biased the results. If this did occur, then the level of association would have been over-estimated by these analyses. Telemetry results, however, indicate that sawfish had a preference for occurring close to mangrove shorelines, providing several advantages such as food and protection from predators (Simpfendorfer et al. 2010). Therefore, actions to preserve and potentially restore these habitats may be necessary for recovery. It should also be noted that sawfish were regularly encountered in heavily modified habitats such as power plant warm water effluents and extensive man-made canal systems. However, it is unknown if the survival, growth rates, or carrying capacity in these habitats is reduced relative to natural habitats. 
The distribution and habitat associations of Pristis pectinata appear to change as they grow. Simpfendorfer et al. (2008) indicated that growth is rapid during the first 2 yr after birth, reducing the risk of predation from large predators, such as sharks, which occur in the same habitats. The smallest juveniles occur in shallow water $(<1 \mathrm{~m})$ often closely associated with mangroves or the shoreline. Results from acoustic telemetry support this observation, showing that animals smaller than approximately $150 \mathrm{~cm}$ selectively use these areas (Simpfendorfer et al. 2010). At sizes above $200 \mathrm{~cm}, P$. pectinata start to occur more frequently in water deeper than $5 \mathrm{~m}$, which may indicate that at this size they are less subject to predation, enabling them to travel farther from the safety of very shallow waters and occupy a broader range of habitats. At sizes over $300 \mathrm{~cm}$, a reasonable proportion of observations was made in deeper water. At this size, they are approaching maturity, or are already mature (Simpfendorfer 2000, Simpfendorfer et al. 2008). These data suggest that at this size, $P$. pectinata begin to spend a considerable proportion of time away from coastal habitats, although the encounters with large animals in shallow water indicate they do return at times, and so occur across a broad range of depths. This may correspond to a change in behavior associated with maturity.

The ontogenetic shift in habitat use by Pristis pectinata means that recovery efforts for different size or maturity classes will need to be focused in different areas. $P$. pectinata $\leq 200 \mathrm{~cm}$ in length have the most specific habitat associations in nearshore areas, and these can be targeted relatively easily with recovery efforts. However, the larger size classes have more varied habitat associations, and recovery efforts will need to be more broadly based or targeted at specific areas that may provide the greatest benefits to the population (e.g. aggregating, mating, feeding).

\section{CONCLUSION}

This study has demonstrated that public encounter data can be a useful tool in the development of recovery efforts for endangered marine species. Despite limitations in how data can be interpreted, information on distribution, size, effects of fishing, and habitat associations were extracted for use in conservation efforts on Pristis pectinata in US waters. This provided a comprehensive view of the current distribution of this species that will help identify priority areas for future efforts to rebuild the population.

Acknowledgements. We thank P. O'Donnell from Rookery Bay Estuarine Research Reserve, all those who reported sawfish encounters, and the charter fishing captains who partici- pated in the Captain's Logbook program. We also thank B. Yeiser and the many interns who assisted with outreach events and material distribution; G. Burgess at the Florida Museum of Natural History for accepting management of the National Sawfish Encounter Database after August 2008; and $\mathrm{S}$. Cooke and 2 anonymous reviewers for valuable comments that improved the manuscript. Field research was conducted in accordance with National Marine Fisheries Service Endangered Species Act permit No. 1352. Funding for the National Sawfish Encounter Database was provided by the National Marine Fisheries Service, Florida Fish and Wildlife Conservation Commission Non-game Program, Disney Wildlife Conservation Fund, National Fish and Wildlife Foundation, Florida Power \& Light, National Geographic Conservation Trust, John Ball Zoo Society, and The Curtis and Edith Munson Foundation.

\section{LITERATURE CITED}

Adams WF, Wilson C (1995) The status of the smalltooth sawfish, Pristis pectinata Latham 1794 (Pristiformes:Pristidae) in the United States. Chondros 6:1-5

Bigelow HB, Schroeder WC (1953) Sawfishes, guitarfishes, skates and rays. Fishes of the western North Atlantic. Mem Sears Found Mar Res 1:1-514

Branstetter S (1990) Early life-history implications of selected carcharhinoid and lamnoid sharks of the northwest Atlantic. In: Pratt HL, Gruber SH, Taniuchi T (eds) Elasmobranchs as living resources: advances in the biology, ecology, systematics and the status of the fisheries. NOAA Tech Rep, NMFS 90, US Dept. of Commerce, Washington, DC, p 17-28

Carlson JK, Osborne J, Schmidt TW (2007) Monitoring the recovery of smalltooth sawfish, Pristis pectinata, using standardized relative indices of abundance. Biol Conserv 136:195-202

- Diemer JE, Speake DW (1983) The distribution of the eastern indigo snake, Drymarchon corias couperi, in Georgia. J Herpetol 17:256-264

Epperly SP, Braun J, Veishlow A (1995) Sea turtles in North Carolina waters. Conserv Biol 9:384-394

Essig RJ, Holliday MC (1991) Development of a recreational fishing survey: the marine recreational fisheries statistics survey case study. Am Fish Soc Symp 12:245-254

Evermann BW, Bean BA (1898) Indian River and its fisheries. US Commission on Fish and Fisheries. Report of the commissioner for the year ending June, 1896. Part XXII. Government Printing Office, Washington, DC

Gese EM (2004) Survey and census techniques for canids. In: Sillero-Zubiri C, Hoffmann M, Macdonald DW (eds) Canids: foxes, wolves, jackals, and dogs. Status survey and conservation action plan. IUCN/SSC Canid Specialist Group, Gland and Cambridge, p 273-279

Goode GB (1884) The fisheries and fishery industries of the United States. Section I: Natural history of useful aquatic animals. Government Printing Office, Washington, DC

Henshall JA (1895) Notes on fishes collected in Florida in 1892. Bull US Fish Comm 14:209-221

Jenness J (2005) Random point generator (randpts.avx) extension for ArcView 3.1, v. 1.3. Jenness Enterprises. Available at www.jennessent.com/arcview/random_points.htm.

Jordan DS, Evermann BW (1896) The fishes of North and Middle America. Bull US Natl Mus No 47. Government Printing Office, Washington, DC

NMFS (National Marine Fisheries Service) (2000) Status review of smalltooth sawfish (Pristis pectinata). Prepared 
by the Smalltooth Sawfish Status Review Team for NMFS, Silver Spring, MD

NMFS (2009) Recovery plan for smalltooth sawfish (Pristis pectinata). Prepared by the Smalltooth Sawfish Recovery Team for NMFS, Silver Spring, MD

Palma L, Beja P, Rodrigues M (1999) The use of sighting data to analyse Iberian lynx habitat and distribution. J Appl Ecol 36:812-824

Pattillo ME, Czapla TE, Nelson DM, Monaco ME (1997) Distribution and abundance of fishes and invertebrates in Gulf of Mexico estuaries, Vol II: Species life history summaries. ELMR Rep No. 11. NOAA/NOS Strategic Environmental Assessments Division, Silver Spring, MD

Peverell SC (2005) Distribution of sawfishes (Pristidae) in the Queensland Gulf of Carpentaria, Australia, with notes on sawfish ecology. Environ Biol Fishes 73:391-402

Pike JR, Shaw JH, Leslie DM Jr, Shaw MG (1999) A geographic analysis of the status of mountain lions in Oklahoma. Wildl Soc Bull 27:4-11

Poulakis GR, Seitz JC (2004) Recent occurrence of the smalltooth sawfish, Pristis pectinata (Elasmobranchiomorphi: Pristidae), in Florida Bay and the Florida Keys, with comments on sawfish ecology. Fla Sci 67:27-35

Quinn T (1995) Using public sighting information to investigate coyote use of urban habitat. J Wildl Manag 59: $238-245$

Seitz JC, Poulakis GR (2002) Recent occurrence of sawfishes (Elasmobranchiomorphi: Pristidae) along the southwest coast of Florida (USA). Fla Sci 65:256-266

Seitz JC, Poulakis GR (2006) Anthropogenic effects on the smalltooth sawfish (Pristis pectinata) in the United States. Mar Pollut Bull 52:1533-1540

Simpfendorfer CA (2000) Predicting recovery rates for endangered western Atlantic sawfishes using demographic analysis. Environ Biol Fishes 58:371-377

Simpfendorfer CA (2002) Smalltooth sawfish: the USA's first endangered elasmobranch? Endang Species Update 19: $53-57$

Editorial responsibility: Steven Cooke, Ottawa, Ontario, Canada
Simpfendorfer CA (2005) Threatened fishes of the world: Pristis pectinata Latham, 1794 (Pristidae). Environ Biol Fishes 73:20

Simpfendorfer CA, Milward NE (1993) Utilisation of a tropical bay as a nursery area by sharks of the families Carcharhinidae and Sphyrnidae. Environ Biol Fishes 37: $337-345$

Simpfendorfer CA, Wiley TR (2005) Determination of the distribution of Florida's remnant sawfish population and identification of areas critical to their conservation. Final Report. Florida Fish and Wildlife Conservation Commission, Tallahassee, FL

> Simpfendorfer CA, Poulakis GR, O'Donnell PM, Wiley TR (2008) Growth rates of juvenile smalltooth sawfish, Pristis pectinata, in the western Atlantic. J Fish Biol 72:711-723

Simpfendorfer CA, Wiley TR, Yeiser BG (2010) Improving conservation planning for endangered sawfish using data from acoustic telemetry. Biol Conserv 143:1460-1469

Snelson FF, Williams SE (1981) Notes on the occurrence, distribution, and biology of elasmobranch fishes of the Indian River Lagoon system, Florida. Estuaries 4:110-120

Springer S (1967) Social organization of shark populations. In: Gilbert PW, Mathewson RF, Rall DP (eds) Sharks, skates and rays. John Hopkins, Baltimore, MD, p 149-174

Stiles FG (1983) On sightings and specimens. Auk 100: $225-226$

Thorburn DC, Morgan DL, Rowland AJ, Gill HS (2007) Freshwater sawfish Pristis microdon Latham, 1794 (Chondrichthyes: Pristidae) in the Kimberley region of Western Australia. Zootaxa 1471:27-41

Thorburn DC, Morgan DL, Rowland AJ, Gill HS, Paling E (2008) Life history notes of the critically endangered dwarf sawfish, Pristis clavata, Garman 1906 from the Kimberley region of Western Australia. Environ Biol Fishes 83:139-145

Westat, Inc. (1989) Investigation of possible recall/reference period bias in national surveys of fishing, hunting and wildlife associated recreation. Final Report to the US Fish and Wildlife Service, Washington, DC

Submitted: February 4, 2010; Accepted: June 30, 2010

Proofs received from author(s): August 13, 2010 